\title{
Isopeptidase activity of human transglutaminase 2: disconnection from transamidation and characterization by kinetic parameters
}

Róbert Király ${ }^{1}$, Kiruphagaran Thangaraju ${ }^{1}, Z^{2}$ sófia Nagy ${ }^{1}$, Russell Collighan ${ }^{3}$, Zoltán Nemes ${ }^{1}$, Martin Griffin ${ }^{3 \#}$ and László Fésüs ${ }^{1,2 \# *}$

${ }^{1}$ Department of Biochemistry and Molecular Biology, ${ }^{2}$ MTA-DE Stem cell, Apoptosis and Genomics Research Group of Hungarian Academy of Sciences, Faculty of Medicine, University of Debrecen, Egyetem tér 1., Debrecen, Hungary H-4012; Phone: +36 52 416-432; Fax: +36 52 314-989; E-mail: fesus@ med.unideb.hu

${ }^{3}$ School of Life and Health Sciences, Aston University, Birmingham, United Kingdom

\#These authors contributed equally to this study

*Corresponding author

The final publication is available at Springer via http://dx.doi.org/[10.1007/s00726-015-2063-5]

\begin{abstract}
Transglutaminase 2 (TG2) is a multifunctional protein with diverse catalytic activities and biological roles. Its best studied function is the $\mathrm{Ca}^{2+}$-dependent transamidase activity leading to formation of $\gamma$-glutamyl- $\varepsilon$-lysine isopeptide crosslinks between proteins or $\gamma$-glutamyl-amine derivatives. TG2 has a poorly studied isopeptidase activity cleaving these bonds. We have developed and characterised TG2 mutants which are significantly deficient in transamidase activity while have normal or increased isopeptidase activity (W332F) and vice versa (W278F). The W332F mutation led to significant changes of both the $\mathrm{K}_{\mathrm{m}}$ and the $\mathrm{V}_{\max }$ kinetic parameters of the isopeptidase reaction of TG2 while its calcium and GTP sensitivity was similar to the wild type enzyme. The W278F mutation resulted in six times elevated amine incorporating transamidase activity demonstrating the regulatory significance of $\mathrm{W} 278$ and $\mathrm{W} 332$ in TG2 and that mutations can change opposed activities located at the same active site. The further application of our results in cellular systems may help to understand TG2 driven physiological and pathological processes better and lead to novel therapeutic approaches where an increased amount of cross-linked proteins correlates with the manifestation of degenerative disorders.
\end{abstract}

Keywords: human transglutaminase 2, isopeptidase activity, $\gamma$-glutamyl-hydrolase, transamidation, regulation of activities, moonlighting enzyme

\section{Introduction}

Transglutaminase 2 (TG2; tissue transglutaminase) is a moonlighting protein with transglutaminase, GTPase, ATPase, protein disulphide isomerase, protein kinase catalytic activities and its functions have been implicated in various biological processes as a catalytically active or an interacting protein partner (Eckert et al. 2013, Wang $\mathrm{Z}$ and Griffin M 2013, Iismaa et al. 2009). It is a member of an enzyme family with 7 catalytically active and one 
inactive additional members; their generally known catalytic activity is calcium-dependent protein crosslinking to form highly resistant $\mathrm{N}^{\varepsilon}$-( $\gamma$-glutamyl)lysine bond between proteins (Lorand and Graham 2003) which has significant roles in physiological and pathological processes, such as blood coagulation, cornification, apoptosis, extracellular matrix stabilization and insoluble aggregate formation in neurodegenerative diseases or fibrotic disorders. Mono- or polyaminylation of glutamine residues of proteins by a transglutaminase occurs in the presence of different amines instead of lysine residues of proteins providing important physiological regulation including the activation of insulin secretion by serotonylation of the Rab small GTPase (Paulmann et al. 2009), and histamine incorporation into fibrinogen (Lai and Greenberg 2013) or gliadin peptides (Qiao et al. 2005) which potentially modulate inflammatory processes. In the absence of any amine donor substrate deamidation of the glutamine residue takes place leading to, for example, a more potent antigen in celiac disease (Shan et al. 2002). The incorporation of a peptide or biogenic amine and deamidation or polyamine linkage modify charges in the target proteins switching on or off the biological process in which they participate.

The transamidation reaction creates proteinase resistant bonds and so far the existence of a specific enzyme which can split these isopeptide bonds in proteins have not been reported. The proteins crosslinked by transamidation are degraded by the proteasomal system or in lysosomes by proteases but they do not touch the isopeptide bond (Guilluy et al. 2007.). Fibrinolysis is responsible for digestion of the highly crosslinked blood clot containing many isopeptide bonds but the $\mathrm{N}^{\varepsilon}$ - $(\gamma$-glutamyl)lysine bond is itself not split and the released $\varepsilon$ $(\gamma$-glutamyl)lysine isodipeptide is detectable in the circulation (Tarcsa and Fesus 1990). There is an enzyme, $\gamma$ glutamilamine cyclotransferase which is able to cleave the $\mathrm{N}^{\varepsilon}$ - $(\gamma$-glutamyl)lysine bond in the dipeptide but this enzyme has significant activity only in the kidney and in the intestine (Raczynski et al. 1975).

It was reported that Factor XIIIa, a member of the transglutaminase family, can reverse crosslinking of $\alpha 2$-plasmin inhibitor to fibrinogen and fibrin potentially regulating the fibrinolytic processes (Ichinose and Aoki 1982; Mimuro et al. 1986). Based on the kinetic and mechanistic similarities to papain it has been proposed that transglutaminases could play a dynamic role in breaking of $\mathrm{N}^{\varepsilon}$ - $(\gamma$-glutamyl)lysine isopeptide bonds (Parameswaran et al. 1997). As a confirmation, the release of a cadaverine linked quencher from oligopeptides by guinea pig liver (gpTG2) and human red blood cell transglutaminases could be shown (Parameswaran et al. 1997, Folk et al. 1967). This data has raised the possibility of the existence of a still unknown regulatory system which can switch on or off transamidase and isopeptidase activities of transglutaminases separately. An enzyme with isopeptidase activity disconnected from transamidation may have particular use in conditions with increased intracellular TG2 activity leading to accumulation of crosslinked proteins in intraneuronal inclusions in multiple neurodegenerative diseases (Martin et al. 2013) or in tissue fibrosis affecting different organs (Johnson et al. 2007). Treatment with specific transglutaminase inhibitors can slow down or stop these pathological unwanted processes but they are not able to reverse them. The development of special inhibitors which are able to block only the transamidase activity of transglutaminases or the potential application of a protein which has enhanced or only isopeptidase activity could provide an alternative way to decrease the load of crosslinked proteins. However, disconnection of the isopeptidase and transamidase activities of any transglutaminase has not been demonstrated so far.

In this study we made an attempt to separate the isopeptidase and transamidase activities of TG2 by site directed mutagenesis. Based on the analysis of published x-ray structures we changed amino acids which are located around the substrate binding cleft and are particularly responsible for the formation of the hydrophobic 
tunnel and the stabilisation of the transition state during the transglutaminase reaction process. Two special mutants were found and characterised, one deficient in transamidase activity with higher isopeptidase activity and another with opposite properties. Based on our study the potential biological application of modified transglutaminases can be considered.

\section{Materials and methods}

\section{Materials}

All materials were purchased from Sigma (St Louis, MO, USA) unless otherwise indicated.

\section{Transglutaminase enzyme preparations}

For more than two decades most of the studies in the transglutaminase field used the cDNA of TG2 cloned by Gentile et al. (1991) which contains Gly at amino acid position 224. We also used this Gly ${ }^{224}$ containing clone in our previous works and at the beginning of this study. However, subsequent analysis of large genomic databases revealed that all the so far sequenced human TG2 alleles have Val at amino acid position 224. The detailed comparison of $\mathrm{Val}$ and Gly containing variants has demonstrated significant difference in their calcium binding affinity and sensitivity affecting both in vitro and in situ transglutaminase activity assays (Kiraly et al. 2013; Kanchan et al. 2013). Based on this data we have decided during the course of this study to change Gly back to Val at position 224 in our TG2 constructs.

The earlier prepared Gly ${ }^{224}$ containing recombinant human TG2 variant and its mutants were expressed in N-terminally (His) ${ }_{6}$-tagged form (pET-30 Ek/LIC-TG2) and purified by Ni-NTA affinity chromatography as described previously (Király et al. 2009). There were no differences in expression level, yield and stability of the mutant proteins as compared to the wild type TG2. After introducing the $\mathrm{Val}^{224} \mathrm{TG} 2$ the expression and purification protocol was refined and for the comparative studies of the two variants and their mutants the following improved protocol was applied: After transformation Rosetta 2 strains were grown in LB broth at $25^{\circ} \mathrm{C}$ to an OD600 0.6 to 0.8 . To induce the expression of His-tagged proteins, the cultures were grown overnight at $16^{\circ} \mathrm{C}$ in the presence of $0.05 \mathrm{mmol} / \mathrm{L}$ isopropyl $\beta$-D-thiogalactoside. The cells were harvested by centrifugation at $4^{\circ} \mathrm{C}$ and then resuspended in $25 \mathrm{ml}$ per litre of culture of ice cold binding buffer (50 mM Tris$\mathrm{HCl}$, pH 7.2, $1 \mathrm{mM}$ EDTA, $5 \mathrm{mM}$ imidazole) with $1 \mathrm{mM}$ PMSF. After cell lysis by sonication (6 times 30 seconds with 1 minute breaks, on ice), and centrifugation (20000g, 30 minutes, $\left.4^{\circ} \mathrm{C}\right)$ the His-tagged protein containing supernatant was loaded onto an equilibrated $(20 \mathrm{ml}$ binding buffer without DTT and then $10 \mathrm{ml}$ binding buffer) His GraviTrap column (GE Healthcare, Little Chalfont, UK). After loading, the column was washed with $10 \mathrm{ml}$ binding buffer, then $10 \mathrm{ml}$ binding buffer with $20 \mathrm{mM}$ imidazole. Finally, the protein was eluted by $10 \mathrm{ml}$ of $500 \mathrm{mM}$ imidazole in binding buffer and the eluate was concentrated using Amicon Centricon-YM $50 \mathrm{MW}$ (Millipore, Billerica, MA). Then the buffer was exchanged to $20 \mathrm{mM}$ Tris-HCl, $\mathrm{pH} 7.2$, with $150 \mathrm{mM} \mathrm{NaCl}, 1 \mathrm{mM}$ dithiothreitol, $1 \mathrm{mM}$ EDTA, and $10 \%$ by volume glycerol. The protein concentration was determined by the Bradford method (Bio-Rad, München, Germany). Finally, protein purity was checked by Coomassie BB staining of SDS-polyacrylamide gels and by Western blots.

\section{End point transamidase activity assay based on labelled amine incorporation on microtiter plate}


The classical microtiter plate assay based on the incorporation of 5-(biotinamido)pentylamine (Zedira) into immobilised N,N-dimethylated casein (DMC) was used as described before (Madi et al. 1998) with the following modifications. The total volume of reaction mixture was $200 \mu$ containing $10 \mathrm{mM}$ dithiothreitol (DTT), $1 \mathrm{mM} \mathrm{N}$-(5-aminopentyl)biotinamide, $5 \mathrm{mM} \mathrm{CaCl}_{2}, 0.5 \mu \mathrm{g}$ TG2 in $0.1 \mathrm{M}$ Tris-HCl buffer, pH 8.5. The reaction was started with addition of $50 \mu$ enzyme solution and performed at $37^{\circ} \mathrm{C}$ for 30 minutes. The cross linked product was detected by streptavidine-alkaline phosphatase and quantitated at $405 \mathrm{~nm}$ by the addition of p-nitro-phenyl phosphate.

End point transamidase activity assay based on labelled glutamine donor peptide incorporation on microtiter plate

Another microtiter plate assay was also used to provide the substrates in other orientation. The commercial CovTest (CovalAb, France) is able to measure specifically the transamidase activity of TG2. The basis of the assay is the incorporation of a short biotinylated peptide (biotin-pepT26, acyl-donor) into spermine (acylacceptor) which was covalently coupled to the surface of the activated plate. We performed the assay based on the article in which the assay was described (Perez et al. 2009). The original plates were ordered from CovalAb and washed with washing solution containing $0.1 \%$ Tween-20 in $0.1 \mathrm{M}$ Tris- $\mathrm{HCl}, \mathrm{pH} 8.5$ at $37^{\circ} \mathrm{C}$ for 15 minutes. Then $50 \mu \mathrm{l}$ of cold reaction mixture containing $20 \mathrm{mM}$ biotin-pepT26 oligopeptide (CovalAb), $30 \mathrm{mM} \mathrm{CaCl}_{2}, 10$ $\mathrm{mM}$ DTT in reaction buffer $(150 \mathrm{mM} \mathrm{NaCl}, 40 \mathrm{mM}$ Tris- $\mathrm{HCl}, \mathrm{pH} 8.3)$ were loaded into the well. The reaction was started by addition of $60 \mu \mathrm{l}$ sample $\left(0.5 \mu \mathrm{g}\right.$ protein) and was incubated at $37^{\circ} \mathrm{C}$ for 25 minutes. Next, after washing 3 times $110 \mu \mathrm{l} /$ well freshly prepared ExtrAvidin peroxidase solution (dilution: 1/5000 in washing buffer containing $1 \% \mathrm{BSA}$ ) was added and incubated for 15 minutes at $37^{\circ} \mathrm{C}$. After washing again 3 times $100 \mu \mathrm{TMB}$ substrate (freshly prepared from TMB tablet using $200 \mu \mathrm{DMSO}$ to resolve the tablet and then it was completed by $9.8 \mathrm{ml}$ phosphate-citrate buffer, pH 5.0 containing $10 \mu 130 \% \mathrm{H}_{2} \mathrm{O}_{2}$ ) was added in each well. The colour reaction was stopped with $50 \mu \mathrm{l} 2.5 \mathrm{~N} \mathrm{H}_{2} \mathrm{SO}_{4}$ and absorbances were read at $450 \mathrm{~nm}$.

\section{Fluorescence isopeptidase assay using Zedira substrates}

Transglutaminase cleaves the isopeptide bond in the synthesised substrate releasing the dark quencher $(2,4$ dinitrophenyl) linked to the cadaverine spacer following the increase of fluorescence from the N-terminally attached fluorophore 2-aminobenzoyl (2-Abz). Based on the suggested protocol the final concentrations in the reaction mixture were: $50 \mathrm{mM}$ Tris- $\mathrm{HCl}, 10 \mathrm{mM} \mathrm{CaCl}_{2}, 100 \mathrm{mM} \mathrm{NaCl}, 0.1 \%$ (w/v) PEG6000, $50 \mu \mathrm{M}$ A102/A101 and $2.8 \mathrm{mM}$ DTT (added with the starting solution which contained the enzyme). The reaction was monitored at $37^{\circ} \mathrm{C}$ by a BIOTEK Synergy 4 or $\mathrm{H} 1$ multiple reader (Ex/Em: 318/413 nm). After subsequent optimisation the isopeptidase assay was performed at pH 6.8 and in the absence of H-Gly-OMe, because it did not have a significant effect on the isopeptidase activity (data not shown). For the analysis of $\mathrm{pH}$ dependence 50 mM MOPS-NaOH based buffer was applied.

\section{Kinetic transamidase assay}

The kinetic transamidase assay was performed with slight modification of a previously published procedure (Lorand et al. 1998): The reaction mixture contained $50 \mathrm{mM}$ Tris-HCl buffer $\mathrm{pH}$ 7.5, $0.5 \mathrm{mM}$ dansyl-cadaverine, $2 \mathrm{mg} / \mathrm{ml} \mathrm{N}, \mathrm{N}^{\prime}$-dimethylated casein, $1 \mathrm{mM}$ DTT, and $\mathrm{CaCl}_{2}$ or $10 \mathrm{mM}$ EDTA. The reaction volume was $100 \mu \mathrm{l}$ 
and the assay was started with the addition of $20 \mu \mathrm{l}$ enzyme (100 nM TG2 final concentration). The activity was calculated based on the linear part of the increasing fluorescence (Ex/Em: 360/490 nm; at $\left.37^{\circ} \mathrm{C}\right)$.

\section{BODIPY-GTP $\gamma$ S nucleotide binding assay}

$500 \mathrm{nM}$ BODIPY-GTP $\gamma \mathrm{S}$ (Invitrogen; McEwen et al. 2001) GTP analog was used to measure nucleotide binding to increasing amounts of TG2 proteins in the presence of $20 \mathrm{~mm}$ HEPES pH 7.5, $150 \mathrm{mM} \mathrm{NaCl}, 0.1 \mathrm{TCEP}, 0.05$ $\%$ Tween-20, $0.1 \mathrm{mM}$ EGTA, $1 \mathrm{mM} \mathrm{MgCl}$.

\section{Results and discussion}

\section{In silico considerations for the separation of transamidase and isopeptidase activity of TG2}

Comparing the known crystal structures of human transglutaminases with corresponding papain structures reveals isolation of the active site of both from ambient water by being buried in the core domain, and surrounded by bulky hydrophobic residues (Pinkas et al. 2007, Chica et al. 2004, Iismaa et al. 2003, Murthy et al. 2002). Although space-filling models in the presence of substrate (inhibitor) show the active site quite exposed to water, in the absence of substrate the water is repelled from the catalytic cavity by hydrophobic tunnels isolated by annealing hydrophobic side chains, such as W241-W332, W278-F334. Also, W180, W337 and Y510 shield the active site from the intrusion of water. In silico modeling of TG2 suggested that suppressive replacements of one or two of these seven residues would make the catalytic core "leaky" to the solvent water molecules without disrupting secondary domain structures. The enhanced access of ambient water to the catalytic site was expected to divert transglutaminase activity towards hydrolysis of the transglutaminase reaction products. To prevent the disruption of the active site we designed the modification to save the hydrophobic character of this site by using amino acids with shorter side chains. Based on this consideration we designed 12 single mutants namely: W180F, W180L, W241F, W241L, W278F, W278L, W332F, W332L, F334L, W337F, W337L, Y516L. These mutants in human TG2 have not yet been purposefully created for the characterisation of their isopeptidase property (Murthy et al. 2002, Iismaa et al. 2003).

2. Effect of changing hydrophobic amino acids around the active site of TG2 on its isopeptidase and transamidase activity

At the beginning of this study the mutants designed above were constructed by site directed mutagenesis in the plasmid clone of the $\mathrm{Gly}^{224}$ containing TG2 variant, since this clone had been used for many studies by different laboratories in the transglutaminase research field until Kanchan et al. (2013) provided data about biochemical differences between $\mathrm{Val}^{224}$ and $\mathrm{Gly}^{224}$ containing variants. To examine the effect of hydrophobic amino acids on transglutaminase activities single mutants of TG2 $\mathrm{Gly}^{224}$ were tested for both isopeptidase and transamidase activities (Fig. 1). Most of these mutants lost both transglutaminase activities, particularly in case of changing Trp to Leu while an Y516L change did not affect them significantly. W337F and W180F mutations resulted in approximately 15-20\% transamidase activities but W180F mutant lost totally its isopeptidase activity. The exchange of $\operatorname{Trp}^{332}$ to Phe and $\operatorname{Trp}^{278}$ to Phe resulted in mutants having only either isopeptidase or transamidase activity, respectively. The $\mathrm{W} 278 \mathrm{~F}$ mutant showed only $7 \%$ remnant isopeptidase activity. Some double mutants 
were also constructed but these did not lead to better separation of isopeptidase and transamidase activities, though the significantly decreased transamidase activity of W337F mutant was compensated by its combination with Y516L exchange.

In earlier studies with rat TG2 only changing $\operatorname{Trp}^{241}$ resulted in significant decrease of transamidase activity (Murthy et al. 2002). In case of human TG2 not only the hydrophobicity of the amino acids around the active site and in the substrate binding area plays a role during the reaction catalysis, but the complexity of the surrounding Trp-s (space filling property, aromatic carbon atom ring containing nitrogen) also have important effect on stabilisation of the transition states of transglutaminase activities (recently reviewed by Keillor et al. 2014). Pinkas et al. (2007) reported that the W332A mutation in human TG2 and the W332F mutation in rat TG2 lead to loss or lower transamidase activity, respectively (Murthy et al. 2002), but in these articles only the transamidase activity was tested. The demonstrated functional difference between orthologous TG2 enzymes also makes comparison difficult (Ruan et al. 2008). A related report came from Keillor's laboratory (2008) after they performed random mutagenesis in gpTG2 targeting selected amino acids around the active site to find special mutants which can form the amide bond in a specific, efficient and economical way. They identified $\operatorname{Tr}^{332}$ which when replaced by Phe or Tyr conferred very low transamidation activity on the enzyme. However, this study did not target $\operatorname{Tr}^{278}$ (W278F). Although our obtained results partially refuted our initial predictions that shorter hydrophobic residues around the active site result in increases of isopeptidase activity, because the W278F mutant lost its isopeptidase and kept its transamidase activity, these demonstrated that the separation and independent regulation of the different type of transglutaminase activities was possible and there was no correlation between transamidase and isopeptidase activities.

\section{Characterisation of transglutaminase mutants with dominant isopeptidase or transamidase activity}

To evaluate the effect of the mutated amino acids on catalytic activities of the wild type human TG2, Gly ${ }^{224}$ was changed to $\mathrm{Val}^{224}$ in case of W332F, W278F, W241F and C277S TG2 mutants (the last two served as controls). (Fig. 2 and Fig. 3). In the isopeptidase assay $\mathrm{Val}^{224}$ containing WT TG2 showed $70 \%$ higher while the W332F and W278F mutants twofold higher activity than their Gly ${ }^{224}$ counterpart (Fig. 2). Val ${ }^{224}$ W332F TG2 presented 1.5 times while Gly ${ }^{224}$ W332F TG2 1.3 times higher isopeptidase activity than the Val ${ }^{224}$ or Gly ${ }^{224}$ WT TG2 variants, respectively, but in case of the $\mathrm{W} 278 \mathrm{~F}$ variants these ratios were 0.33 and 0.18 . In case of the control W241F (conserved Trp) and C277S (active site) mutants the Gly to Val exchange did not show detectable modification of their isopeptidase activity.

In an end-point transamidase activity assay $\mathrm{Val}^{224}$ WT TG2 exhibited $33 \%$ increases and both W332F and W278F mutants showed slightly higher activity than their Gly ${ }^{224}$ variants. Using a kinetic transamidase assay we also observed that $\mathrm{Val}^{224}$ variants have higher activities; $\mathrm{Val}^{224}$ WT TG2 exhibited a two fold increase compared to Gly ${ }^{224}$ WT TG2. Surprisingly, in this kinetic transamidase assay both variants of the W278F mutant presented significantly increased, 5.8 times higher activities compared to the appropriate WT TG2 variants. Using the kinetic assay the percentage of remaining transamidase activity in case of $\mathrm{Val}^{224}$ and $\mathrm{Gly}^{224} \mathrm{~W} 332 \mathrm{~F}$ mutants compared to the appropriate WT variant were higher (47\% and 73\%, respectively) than in the end-point assay (18\% and 7\%, respectively). The Gly ${ }^{224}$ variant of the W241F control mutant, which showed only very low transamidase activity in the kinetic assay, was 4 times more active in the Val ${ }^{224}$ containing form confirming the 
structural significance of amino acid position 224 in TG2 (Kanchan et al. 2013). The C277S variants were totally inactive in all activity measurements (data not shown).

Taken together the $\mathrm{Val}^{224}$ containing enzymes demonstrated consequently higher isopeptidase and transamidase activities compared to their $\mathrm{Gly}^{224}$ variants. Therefore, we decided to use the Val ${ }^{224} \mathrm{TG}_{2 \mathrm{~s}}$ for further characterisations labelling them as TG2 WT (no mutation), TG2-I (W332F, isopeptidase active and transamidase deficient) and TG2-T (W278F, transamidase active and isopeptidase deficient).

Both isopeptidase activity of TG2-I and transamidase activity of TG2-T mutants exhibited similar but a slightly smaller $\mathrm{Ca}^{2+}$ sensitivity compared to WT TG2 based on their EC50 values (Fig. S1). According to the fitted calcium sensitivity curve they reached the maximum level of activity of the wild type in each case at a lower calcium concentration than was needed for the wild type TG2 suggesting that their global structure is intact, there is no significant molecular dynamical deviance and local effects are responsible for disconnection of isopeptidase and transamidase activities.

The actual $\mathrm{pH}$ can influence the ratio of the different type of transglutaminase reactions: deamidation and isopeptidase type of transglutaminase activities prefer acidic $\mathrm{pH}$ opposed to transamidation which favours alkaline pH (Fleckenstein et al. 2002; Adamczyk et al. 2013). The effect of pH was also tested on the isopeptidase and transamidase activities of TG2-I and TG2-T mutant enzymes, respectively, and both activities showed responsiveness similar to the wild type enzyme (Fig. S2) suggesting that the mutations did not influence catalytic steps driven by acidic-alkaline changes.

The commercial supplier of the isopeptidase substrates suggested Tris- $\mathrm{HCl}$ buffer at $\mathrm{pH} 7.5$ to perform the isopeptidase assays but during optimization of the assay increased activities were observed at acidic $\mathrm{pH}$ and therefore $\mathrm{pH} 6.8$ was selected as the standard $\mathrm{pH}$ throughout the experiments. Some control isopeptidase measurements were performed in MOPS buffer which resulted in the same activity values as in experiments done in Tris- $\mathrm{HCl}$ buffer (Fig. S2) confirming the precision of the $\mathrm{pH}$ setting with Tris-HCl buffer.

\section{TG2-I has a higher potential to cleave $\gamma$-glutamylamine bonds than the wild type TG2}

To further characterise the effect of the $\mathrm{W} 332 \mathrm{~F}$ mutation kinetic parameters of isopeptidase reaction were determined using two commercially available Zedira substrates (A101: Abz-NE(Cad-Dnp)EQVSPLTLLK-OH, derived from N-terminal dodecapeptide of a2-plasmin inhibitor and A102: Abz-APE(Cad-Dnp)QEA-OH, derived from human osteonectin) to reveal the explanation of the separation of transamidase and isopeptidase activities (Fig. 4a and 4b). Using the A102 compound which serves as a TG2 isopeptidase assay substrate, the W332F mutation resulted in a similar $\mathrm{V}_{\max }$ value but the $\mathrm{K}_{\mathrm{m}}$ dropped more than $50 \%$ compared to the wild type enzyme. In case of the A101 compound provided as a Factor XIIIA assay substrate this mutation led to almost a doubled $\mathrm{V}_{\max }$ without changing the $\mathrm{K}_{\mathrm{m}}$ value which was lower than in case of the A102 substrate. These data suggest that the W332F mutation modifies both the substrate binding and the catalytic mechanism of transglutaminase reactions.

The affinity change towards isopeptidase substrates could be tested by the addition of different types of transamidase substrates as competitive inhibitors and the determination of how they influence the isopeptidase substrate binding. Both glutamine containing acyl donor and primary- or polyamine acyl acceptor substrates inhibit transamidase activity in a reversible way due to competition with the substrates. We found that the amine 
donor biotin-cadaverine (tested up to $500 \mu \mathrm{M}$ concentration; data not shown) and ethyl-amine did not inhibited the isopeptidase activity but the N-terminal $\alpha 2$-plasmin inhibitor peptide (PI2: NQEQVSPLTLLK; N-terminal dodekapeptide of $\alpha 2$-plasmin inhibitor; glutamine donor) inhibited it in a concentration dependent manner (Fig. $4 \mathrm{c}$ and $4 \mathrm{~d})$. The PI2 glutamine donor peptide is the transamidase substrate form of the A101 isopeptidase substrate (PI2 with the $\gamma$-glutamyl cadaverine linked quencher) and based on the inhibitory curves TG2-I has a lower affinity for PI2 than the wild type (based on its lower inhibitory effect on TG2-I). This seems unusual considering that the WT and TG2-I mutant have the same affinity for this peptide in its isopeptidase substrate form. This feature suggests that human TG2 has a different affinity or preference toward previously transglutaminase modified or crosslinked proteins and both the glutamine and that the amine donor part could determine the efficiency of the isopeptidase activity.

\section{TG2-I has weak nucleotide binding without functional consequence}

It is known that $\mathrm{Ca}^{2+}$ and nucleotides regulate reciprocally transglutaminase reactions. BODIPY FL GTP $\gamma \mathrm{S}$ binds to GTP-binding proteins following increases of fluorescence providing a non radioactive alternative tool to analyse protein-nucleotide interaction. The functional integrity of the mutants and the potential conformational changes due to the mutations were examined by their nucleotide binding (Fig. 5a). In case of the TG2-I mutant very weak while in case of the TG2-T mutant higher BODIPY FL GTP $\gamma \mathrm{S}$ binding was observed as compared to the WT enzyme. The C277S and W241F mutants were used as controls because their GTP binding features have been already published (Murthy et al 2002; Ruan et al 2008; Gundemir and Johnson 2009); the results were congruent with the previously published data confirming the reliability of the assay used by us. The lower nucleotide binding of TG-I was similar to that of the C277S mutant.

In spite of its weak binding to TG2-I the functional effect of the nucleotide on the isopeptidase activity was evident (Fig. 5b; Table S1, Fig. S3). Furthermore a significant difference has been observed in the nucleotide sensitivity of isopeptidase and transamidase activities; nucleotides had stronger inhibitory effect on the isopeptidase activity of the wild type TG2 than on its transamidase activity (Table S1). It was a surprise that TG2-I presented functional nucleotide sensitivity similar to the wild type TG2 despite its weak GTP binding while TG2-T presented slightly higher nucleotide binding affinity and accordingly higher GTP sensitivity compared to the wild type. One possibility is that the interaction of BODIPY-GTP $\gamma \mathrm{S}$ with non canonical nucleotide binding sites of TG2 does not lead to the increases of its fluorescent intensity (Kiraly et al. 2009; Liu et al. 2002) or the slight difference between the natural and labelled nucleotides could be responsible for these deviances. It cannot be excluded either that the replacement of $\operatorname{Tr}^{332}$, similarly to $\mathrm{Cys}^{277}$, may break the integrity and balance of the highly conserved interface between the 159-173 nucleotide binding loop and the amino acids surrounding the active site (Murthy et al. 2002) modifying the affinity of nucleotide binding while still keeping its regulatory function.

\section{Conclusions and Perspectives}

In this study we found that the separation of different catalytic activities of transglutaminase 2 could be achieved by replacement of amino acids around the active site (Fig. 3) resulting in TG2 mutants which either prefer 
isopeptidase activity or exhibit almost 6 times higher transamidase activity in a soluble phase kinetic assay. The characterised mutants can serve as tools to develop cellular models for better examination of biological functions and applications of transglutaminases. The TG2-T mutant with elevated transamidase and deficient isopeptidase activity can help to understand better the role of amine incorporation in cellular phenomena and may be used for production of covalently crosslinked biopolymers. The use of TG2-I with its high isopeptidase activity without transamidation potential could reveal whether crosslinking and transamidation of proteins in cells and body fluids are reversible or not. It could also provide a potential therapeutic tool to reverse pathological processes in which the increased crosslinking of proteins are in correlation with the severity of the disease manifestation as in neurodegenerative disorders and liver, kidney or lung fibrosis.

Reversible covalent modification of proteins have crucial regulatory functions in cells. Protein phosphorylation by diverse kinases modify proteins stitching phosphate groups to Tyr, Ser or Thr residues to regulate many cellular phenomena and a limited number of broad specificity phosphatases are available to reverse this reaction. Ubiquitin ligases form isopeptide bonds between proteins and ubiquitin which can be reversed by deubiquitinases regulating the fates and the roles of many proteins in different cell compartments. Is it possible that transglutaminases can also regulate critical cellular functions by formation and breaking of protein-bound $\gamma$-glutamyl-linked crosslinks and amine derivatives and both of these activities reside in one enzyme? For example TG2 mediated covalent incorporation of biogenic amines into small GTPase plays a role in the activation of insulin secretion (Paulmann et al. 2009; Vowinckel et al. 2012) but it is still not clear how this activation is reversed. Isopeptidase activity of TG2 may remove the activating amine and similar reversible transglutaminase regulated system may exist where still unknown local cellular changes may lead enhanced transamidase, then isopeptidase activity switching on and off biochemical processes.

\section{Acknowledgement}

The authors are grateful to Dr. Máté Demény for the critical reading of the manuscript. This work was supported by the Research University grant from University of Debrecen (RH/885/2013), the Hungarian Scientific Research Fund (OTKA NK 105046), the New Hungary Development Plan via the TÁMOP-4.2.2.A11/1/KONV-2012-0023 "VÉD-ELEM" project co-financed by the European Social Fund, the European Union Framework Programme 7 TRANSCOM IAPP 251506 and TRANSPATH ITN 289964 and the European Union and the State of Hungary, co-financed by the European Social Fund in the framework of the TÁMOP 4.2.4. A/211-1-2012-0001 'National Excellence Programme' which provided personal support to R.K.

\section{Conflict of interest}

The authors declare that they have no conflict of interest. 


\section{References}

Adamczyk M, Heil A and Aeschlimann D (2013) Real-time fluorescence assay for monitoring transglutaminase activity. BMG LABTECH's Application Note 234, Rev. 04/2013

Chica RA, Gagnon P, Keillor JW, Pelletier JN (2004) Tissue transglutaminase acylation: Proposed role of conserved active site Tyr and Trp residues revealed by molecular modeling of peptide substrate binding. Protein Sci 13:979-91

Eckert RL, Kaartinen MT, Nurminskaya M, Belkin AM, Colak G, Johnson GV, Mehta K (2014)

Transglutaminase regulation of cell function. Physiol Rev 94:383-417

Fleckenstein B, Molberg Ø, Qiao SW, Schmid DG, von der Mülbe F, Elgstøen K, Jung G, Sollid LM (2002) Gliadin $\mathrm{T}$ cell epitope selection by tissue transglutaminase in celiac disease. Role of enzyme specificity and $\mathrm{pH}$ influence on the transamidation versus deamidation process. J Biol Chem 277:34109-16

Folk JE, Cole PW, Mullooly JP (1967) Mechanism of action of guinea pig liver transglutaminase. 3. The metaldependent hydrolysis of p-nitrophenyl acetate; further observations on the role of metal in enzyme activation. $\mathrm{J}$ Biol Chem 242:2615-21

Gentile V, Saydak M, Chiocca EA, Akande O, Birckbichler PJ, Lee KN, Stein JP, Davies PJ (1991) Isolation and characterization of cDNA clones to mouse macrophage and human endothelial cell tissue transglutaminases. J Biol Chem 266:478-83

Guilluy C, Rolli-Derkinderen M, Tharaux PL, Melino G, Pacaud P, Lorand G (2007) Transglutaminasedependent RhoA activation and depletion by serotonin in vascular smooth muscle cells. J Biol Chem 282:291828

Gundemir S, Johnson GV (2009) Intracellular localization and conformational state of transglutaminase 2: implications for cell death. PLoS One 4(7):e6123. doi: 10.1371/journal.pone.0006123.

Ichinose A and Aoki N (1982) Reversible cross-linking of alpha 2-plasmin inhibitor to fibrinogen by fibrinstabilizing factor. Biochim Biophys Acta 706:158-64

Iismaa SE, Holman S, Wouters MA, Lorand L, Graham RM, Husain A (2003) Evolutionary specialization of a tryptophan indole group for transition-state stabilization by eukaryotic transglutaminases. Proc Natl Acad Sci U S A 100:12636-12641

Iismaa SE, Mearns BM, Lorand L, Graham RM (2009) Transglutaminases and disease: lessons from genetically engineered mouse models and inherited disorders. Physiol Rev 89:991-1023 
Johnson TS, Fisher M, Haylor JL, Hau Z, Skill NJ, Jones R, Saint R, Coutts I, Vickers ME, El Nahas AM, Griffin M (2007) Transglutaminase inhibition reduces fibrosis and preserves function in experimental chronic kidney disease. J Am Soc Nephrol 18:3078-88

Kanchan K, Ergülen E, Király R, Simon-Vecsei Z, Fuxreiter M, Fésüs L (2013) Identification of a specific one amino acid change in recombinant human transglutaminase 2 that regulates its activity and calcium sensitivity. Biochem J 455:261-72

Keillor JW, Chica RA, Chabot N, Vinci V, Pardin C, Fortin E, Gillet SMFG, Nakano Y, Kaartinen MT, Pelletier JN, Lubell WD (2008) The bioorganic chemistry of transglutaminase: From mechanism to inhibition and engineering. Can J Chem 86:271-276

Keillor JW, Clouthier CM, Apperley KY, Akbar A, Mulani A (2014) Acyl transfer mechanisms of tissue transglutaminase. Bioorg Chem 57:186-97

Király R, Csosz E, Kurtán T, Antus S, Szigeti K, Simon-Vecsei Z, Korponay-Szabó IR, Keresztessy Z, Fésüs L (2009) Functional significance of five noncanonical Ca2+-binding sites of human transglutaminase 2 characterized by site-directed mutagenesis. FEBS J 276:7083-7096

Király R, Barta E and Fésüs L (2013) Polymorphism of transglutaminase 2: unusually low frequency of genomic variants with deficient functions. Amino Acids 44:215-25

Lai TS, Greenberg CS (2013) Histaminylation of fibrinogen by tissue transglutaminase-2 (TGM-2): potential role in modulating inflammation. Amino Acids 45:857-64.

Liu S, Cerione RA, Clardy J (2002) Structural basis for the guanine nucleotide-binding activity of tissue transglutaminase and its regulation of transamidation activity. Proc Natl Acad Sci U S A 99:2743-7

Lorand L, Graham RM (2003) Transglutaminases: crosslinking enzymes with pleiotropic functions. Nat Rev Mol Cell Biol 4:140-56.

Lorand L, Stern AM, Velasco PT (1998) Novel inhibitors against the transglutaminase-catalysed crosslinking of lens proteins. Exp Eye Res 66:531-6

Mádi A, Punyiczki M, di Rao M, Piacentini M, Fésüs L (1998) Biochemical characterization and localization of transglutaminase in wild-type and cell-death mutants of the nematode Caenorhabditis elegans. Eur J Biochem 253:583-90 
Martin A, Giuliano A, Collaro D, De Vivo G, Sedia C, Serretiello E, Gentile V (2013) Possible involvement of transglutaminase-catalyzed reactions in the physiopathology of neurodegenerative diseases. Amino Acids 44:111-8

Mimuro J, Kimura S and Aoki N (1986) Release of alpha 2-plasmin inhibitor from plasma fibrin clots by activated coagulation factor XIII. Its effect on fibrinolysis. J Clin Invest 77: 1006-13

McEwen DP, Gee KR, Kang HC, Neubig RR (2001) Fluorescent BODIPY-GTP analogs: real-time measurement of nucleotide binding to G proteins. Anal Biochem 291:109-17

Murthy SN, Iismaa S, Begg G, Freymann DM, Graham RM, Lorand L (2002) Conserved tryptophan in the core domain of transglutaminase is essential for catalytic activity. Proc Natl Acad Sci U S A 99:2738-42

Parameswaran KN, Cheng XF, Chen EC, Velasco PT, Wilson JH, Lorand L (1997) Hydrolysis of gamma:epsilon isopeptides by cytosolic transglutaminases and by coagulation factor XIIIa. J Biol Chem 272:10311-7

Paulmann N, Grohmann M, Voigt JP, Bert B, Vowinckel J, Bader M, Skelin M, Jevsek M, Fink H, Rupnik M, Walther DJ (2009) Intracellular serotonin modulates insulin secretion from pancreatic beta-cells by protein serotonylation. PLoS Biol 7(10):e1000229. doi: 10.1371/journal.pbio.1000229.

Perez Alea M, Kitamura M, Martin G, Thomas V, Hitomi K, El Alaoui S (2009) Development of an isoenzymespecific colorimetric assay for tissue transglutaminase 2 cross-linking activity. Anal Biochem 389:150-6

Pinkas DM, Strop P, Brunger AT, Khosla C (2007) Transglutaminase 2 undergoes a large conformational change upon activation. PLoS Biol 5(12):e327

Qiao SW, Piper J, Haraldsen G, Oynebråten I, Fleckenstein B, Molberg O, Khosla C, Sollid LM (2005) Tissue transglutaminase-mediated formation and cleavage of histamine-gliadin complexes: biological effects and implications for celiac disease. J Immunol 174:1657-63

Raczyński G, Snochowski M, Buraczewski S (1975) Metabolism of epsilon-(gamma-L-glutamyl)-L-lysine in the rat. Br J Nutr 34:291-6

Ruan Q, Tucholski J, Gundemir S, Johnson Voll GV (2008) The Differential Effects of R580A Mutation on Transamidation and GTP Binding Activity of Rat and Human Type 2 Transglutaminase. Int J Clin Exp Med $1: 248-59$

Shan, L., Ø. Molberg, I. Parrot, F. Hausch, F. Filiz, G. M. Gray, L. M. Sollid, C. Khosla (2002) Structural basis for gluten intolerance in celiac sprue. Science 297:2275. 
Tarcsa E, Fesus L (1990) Determination of epsilon (gamma-glutamyl)lysine crosslink in proteins using phenylisothiocyanate derivatization and high-pressure liquid chromatographic separation. Anal Biochem $186: 135-40$

Vowinckel J, Stahlberg S, Paulmann N, Bluemlein K, Grohmann M, Ralser M, Walther DJ (2012)

Histaminylation of glutamine residues is a novel posttranslational modification implicated in G-protein signaling. FEBS Lett 586:3819-24

Wang Z, Griffin M (2012) TG2, a novel extracellular protein with multiple functions. Amino Acids 42:939-49

\section{Figure legends:}

Fig. 1 Comparison of the isopeptidase and transamidase activities of single (a) and double (b) mutant TG2 proteins containing $\mathrm{Gly}^{224}$. Isopeptidase and transamidase activities were tested using isopeptidase reaction substrate from Zedira (A102) and a microtiter plate method (biotin-pepT26 incorporation into immobilized spermine; Perez Alea M et al. 2009) in the presence of 10 and $0.5 \mu \mathrm{g}$ enzyme, respectively. Activity is shown as a percentage of the activity of $\mathrm{Gly}^{224}$ WT TG2. Data are presented as means with \pm SD from two separate experiments done in triplicate. The "G" in the name of the mutants means that they contain Gly at 224 amino acid position.

Fig. 2 Comparison of the isopeptidase and transamidase activities of the selected mutant TG2 proteins containing $\mathrm{Val}$ at 224 amino acid position. Isopeptidase and transamidase activities were tested using, isopeptidase reaction (A102 substrate; Zedira), kinetic transamidase assay (N,N-dimethyl casein+dansylcadaverine) and endpoint microtiter plate transamidase method (biotin-T26 peptide incorporation into immobilized spermine) in the presence of $10,0.8$, or $0.5 \mu \mathrm{g}$ enzyme, respectively. The relative activities are calculated as a percentage of the activity values of the most abundant human $\mathrm{Val}^{224}$ containing WT TG2. Data are presented as means with $\pm \mathrm{SD}$ from two or three separate experiments done in triplicate. Variants of C277S active site mutants did not show detectable activity in these assays (data not shown).

Fig. 3 Mutagenised hydrophobic amino acids around the catalytic triad on the GDP-bound closed (a) and "open" form (b) of human TG2 X-ray structure (Pdb codes: 1KV3 and 2Q3Z, respectively). The replacement of these amino acids result in lost or significant decrease of transglutaminase activities but our data demonstrate that some modifications could lead to "super transglutaminases" explaining special features as biological glue or scissor very likely influencing physiological and pathological processes. On the grey C $\alpha$ backbone of TG2 balls and sticks represent the catalytic triad (red; Cys277, His335, Asp358) and the mutated amino acids (grey). 
Fig. 4 Kinetic characterisation of the isopeptidase reaction of TG2-I and WT TG2. (a, b) Determination of kinetic parameters for isopeptidase activity of TG2-I mutant and WT TG2 with the available commercial substrates A101 and A102. Data are presented as means with \pm SD from three separate experiments done in triplicate. The data analysis and curve fitting was done by GraphPad Prism 5. (c, d) Effect of ethyl-amine and an $\alpha 2$-plasmin inhibitor derived dodecapeptide on isopeptidase activity in the presence of $50 \mu \mathrm{M}$. A102 substrate and $10 \mathrm{mM} \mathrm{CaCl}_{2}$. EA (ethyl-amine) was applied in 0.05, 0.2, 1.0 and 5.0 mM PI2 was applied in 0.05, 0.1, 0.5 and $2.0 \mathrm{mM}$ concentration. Data are presented as means with $\pm \mathrm{SD}$ from two separate experiments done in duplicate.

Fig. 5 Comparison of BODIPY-GTP $\gamma \mathrm{S}$ binding of mutant and WT TG2 proteins and the inhibitory effect of GTP $\gamma \mathrm{S}$ on the isopeptidase activity. (a) Dose response curve for TG2 enzyme amount. BODIPY-GTP $\gamma \mathrm{S}$ (500 $\mathrm{nM}$ ) was dissolved in buffer containing $20 \mathrm{mM}$ HEPES pH 7.5, $150 \mathrm{mM} \mathrm{NaCl}, 1 \mathrm{mM}$ TCEP, $1 \mathrm{mM} \mathrm{MgCl}_{2}, 0.05$ $\%$ Tween-20 and 0.1 mM EGTA. The change in the fluorescence intensity (Ex/Em: 485/520 nm) was determined after 15 minutes of incubation. Binding is shown as a percentage of maximum binding in case of WT TG2. Data are presented as means with \pm SD from three separate experiments done in triplicate. (b) Dose response curve for GTP $\gamma \mathrm{S}$ on isopeptidase activity shown as a percentage of the activity of WT TG2. Different concentrations of GTP $\gamma \mathrm{S}$ were used in presence of 1 or $10 \mathrm{mM} \mathrm{CaCl}_{2}$ and $10 \mu \mathrm{g}$ of proteins. Data are presented as means with $\pm \mathrm{SD}$ from two separate experiments done in triplicate. 
Fig. 1.

(a)

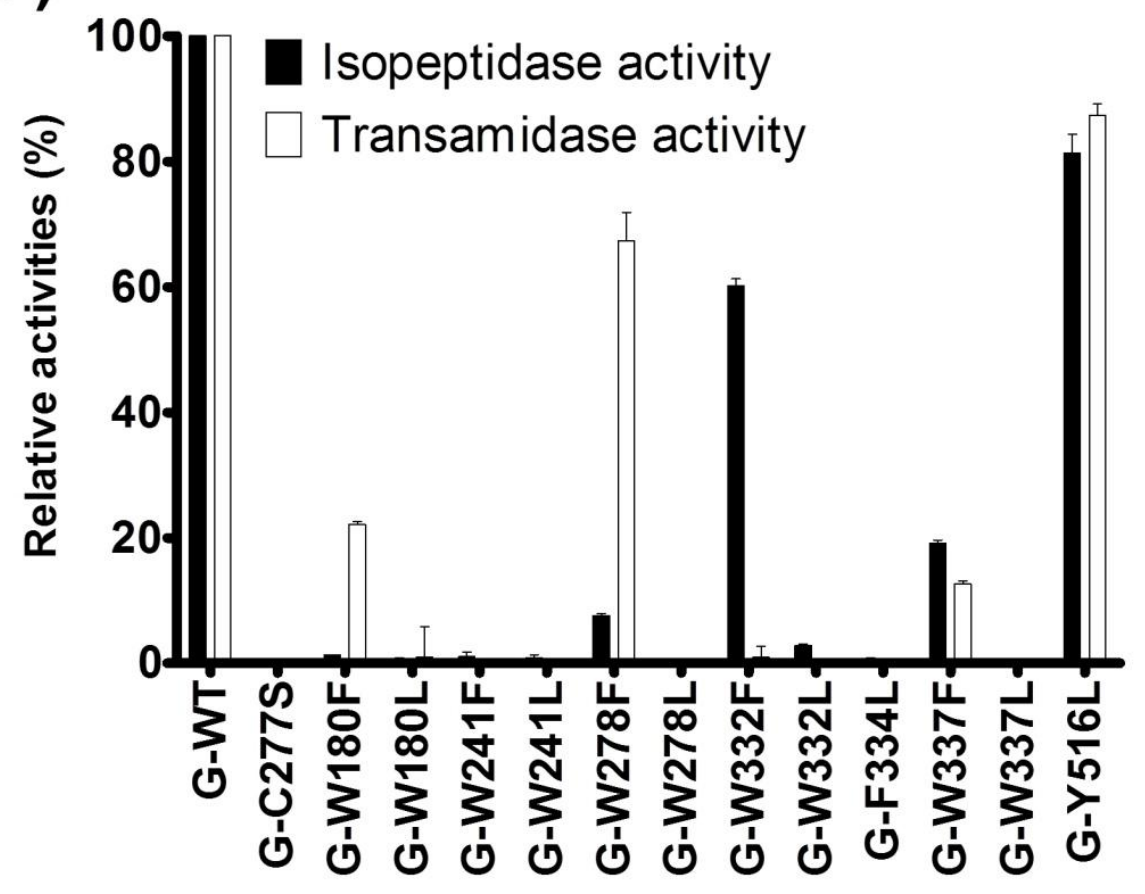

(b)

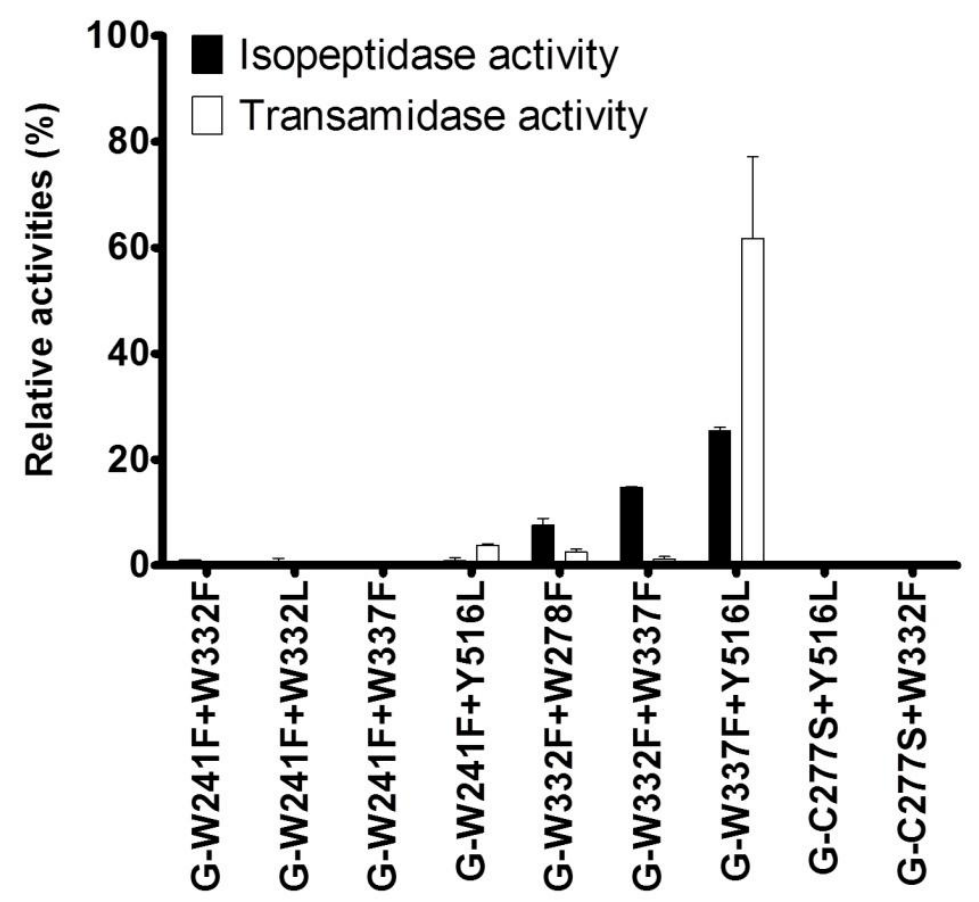


Fig. 2.

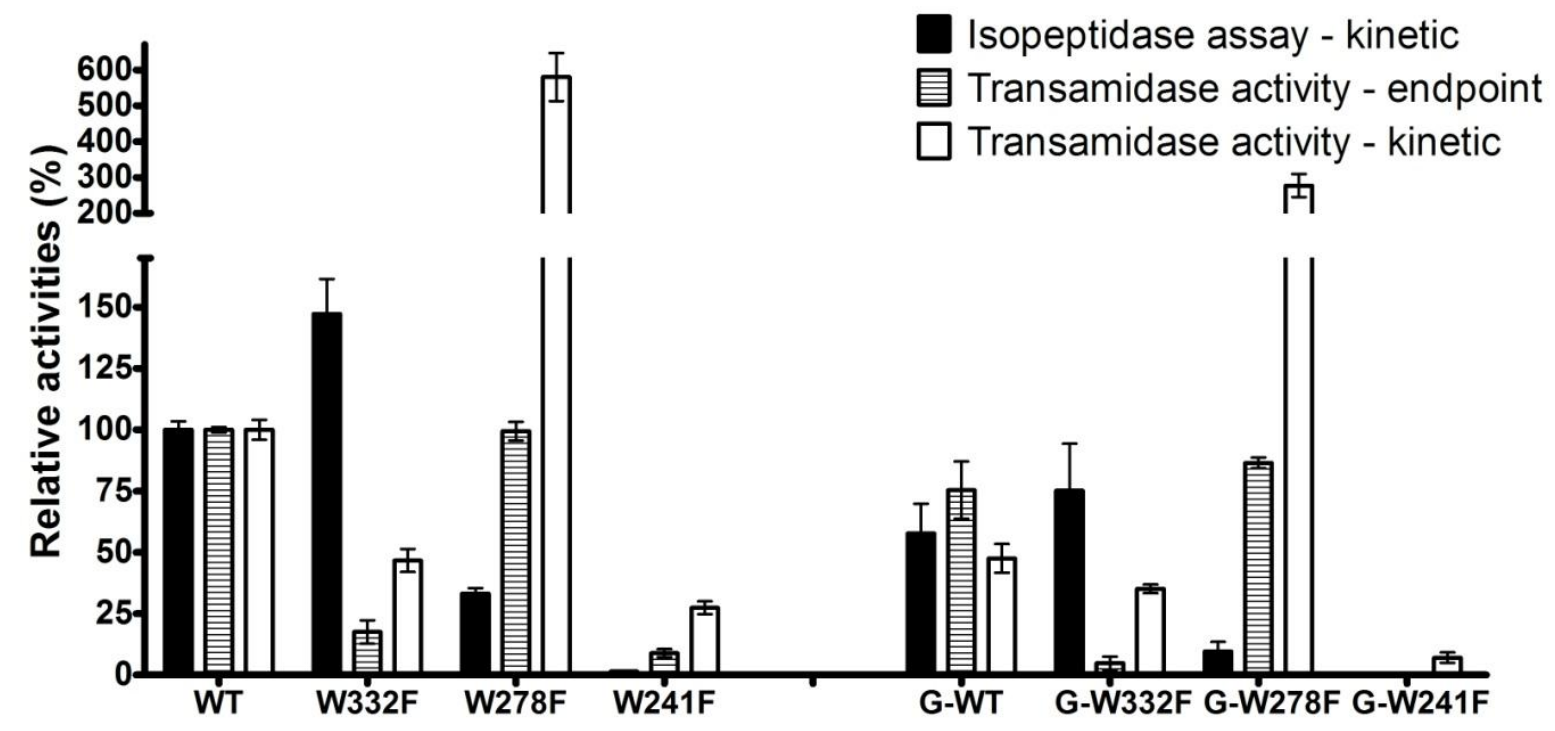


Fig. 3.

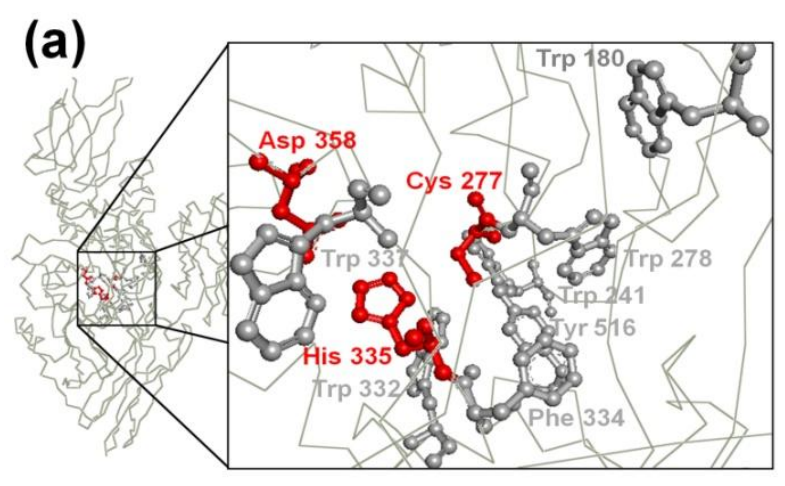

(b)

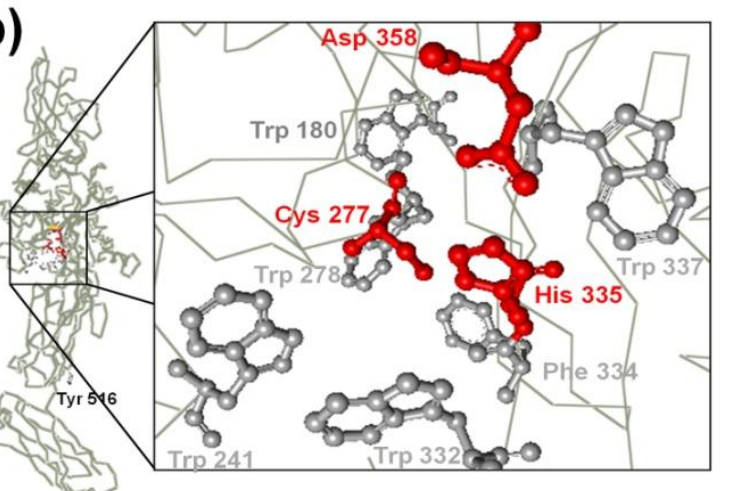


Fig. 4.

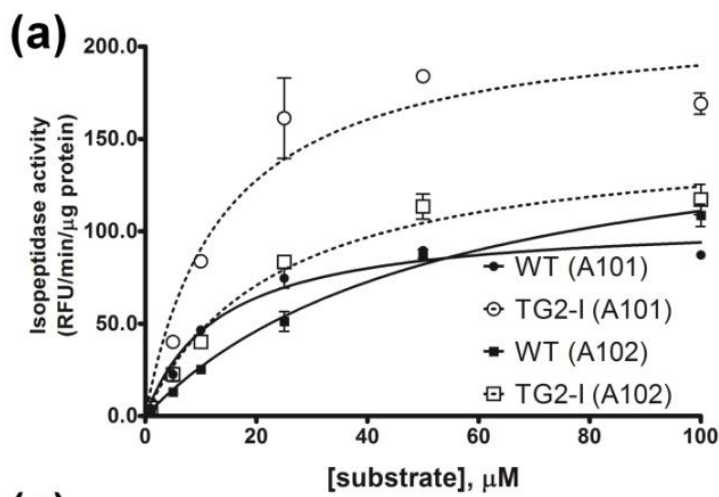

(c)

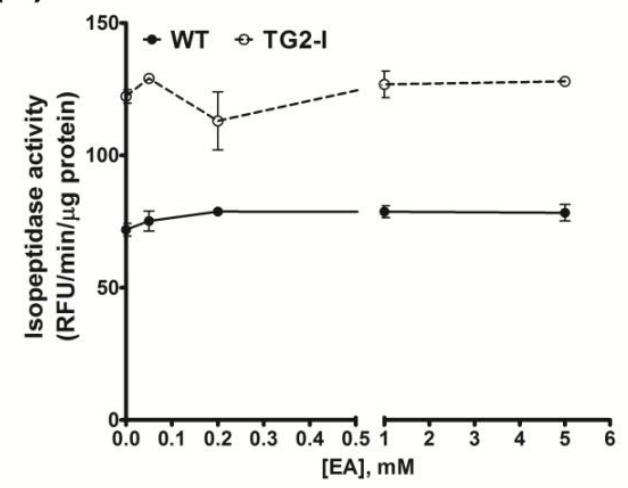

(b)

\begin{tabular}{ccc}
\hline Enzyme / substrate & $\begin{array}{c}\mathrm{V}_{\max } \\
(\mathrm{RFU} / \mathrm{min} / \mu \mathrm{g} \text { protein })\end{array}$ & $\begin{array}{c}\mathrm{K}_{\mathrm{m}} \\
(\mu \mathrm{M})\end{array}$ \\
\hline WT TG2 / A101 & $106.4 \pm 5.3$ & $13.21 \pm 2.2$ \\
TG2-I / A101 & $216.1 \pm 17.6$ & $13.89 \pm 3.7$ \\
WT TG2 / A102 & $171.3 \pm 11.3$ & $54.34 \pm 7.4$ \\
TG2/I / A102 & $160.3 \pm 9.3$ & $23.38 \pm 3.9$ \\
\hline
\end{tabular}

(d)

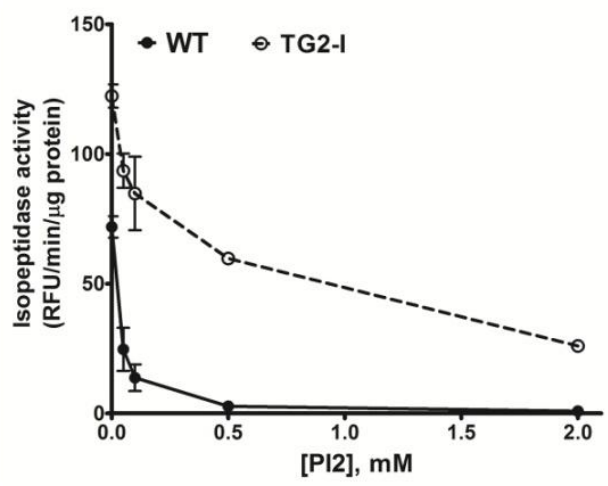


Fig. 5.

(a)

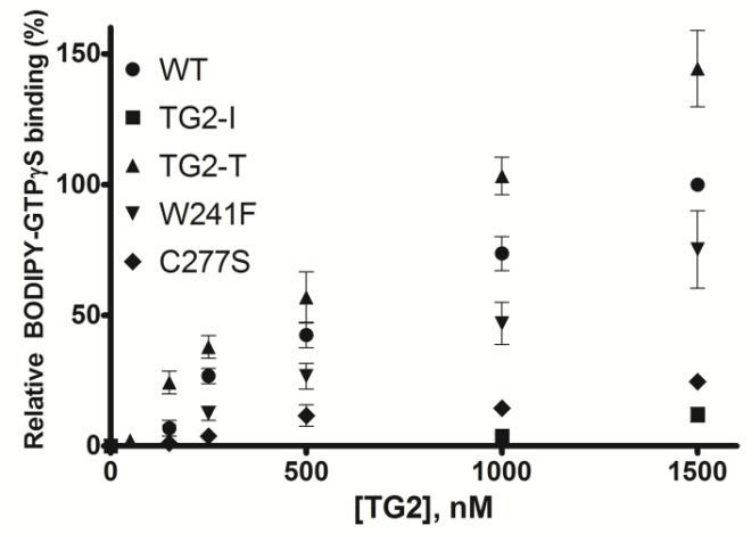

(b)

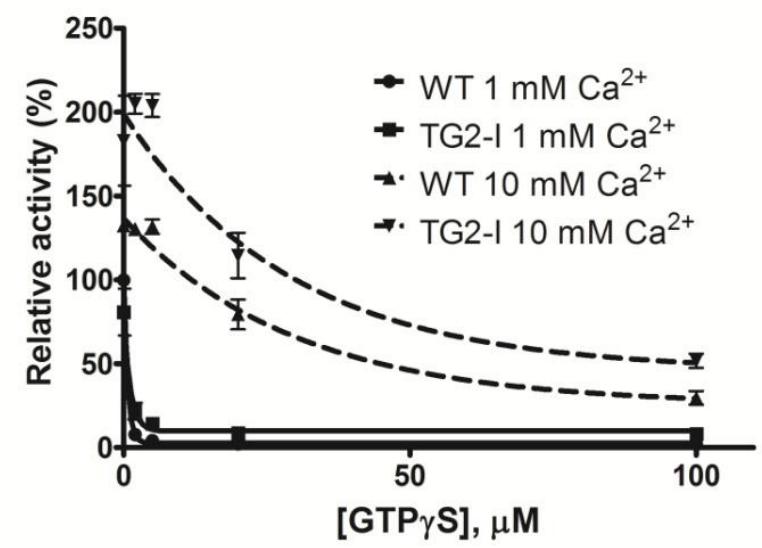




\section{AMINO ACIDS - SUPPLEMENTARY FILE:}

\section{Isopeptidase activity of human transglutaminase 2: disconnection from transamidation and}

characterization by kinetic parameters

Robert Kiraly ${ }^{1}$, Kiruphagaran Tangaraju ${ }^{1}$, Zsófia Nagy ${ }^{1}$, Russell Collighan ${ }^{3}$, Zoltán Nemes ${ }^{1}$, Martin Griffin $^{3 \#}$ and László Fésüs ${ }^{1,2 \# *}$

${ }^{1}$ Department of Biochemistry and Molecular Biology, ${ }^{2}$ MTA-DE Stem cell, Apoptosis and Genomics Research Group of Hungarian Academy of Sciences, Faculty of Medicine, University of Debrecen, Egyetem tér 1., Debrecen, Hungary H-4012; Phone: +36 52 416-432; Fax: +36 52 314-989; E-mail: fesus@ med.unideb.hu ${ }^{3}$ School of Life and Health Sciences, Aston University, Birmingham, United Kingdom

\#These authors contributed equally to this study

*Corresponding author

The W332F and the W278F mutants have only slightly lower $\mathrm{Ca}^{2+}$-sensitivity compared to the wild type TG2

(a)

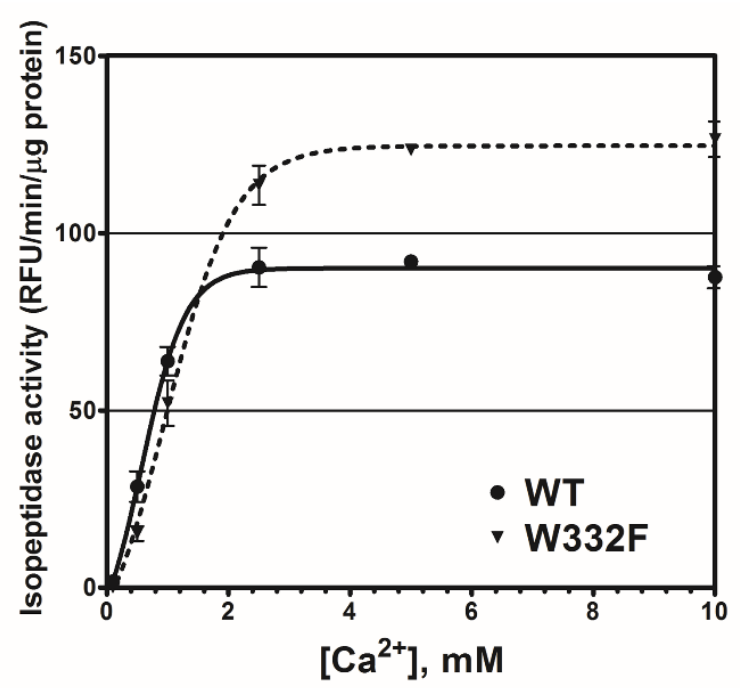

(b)

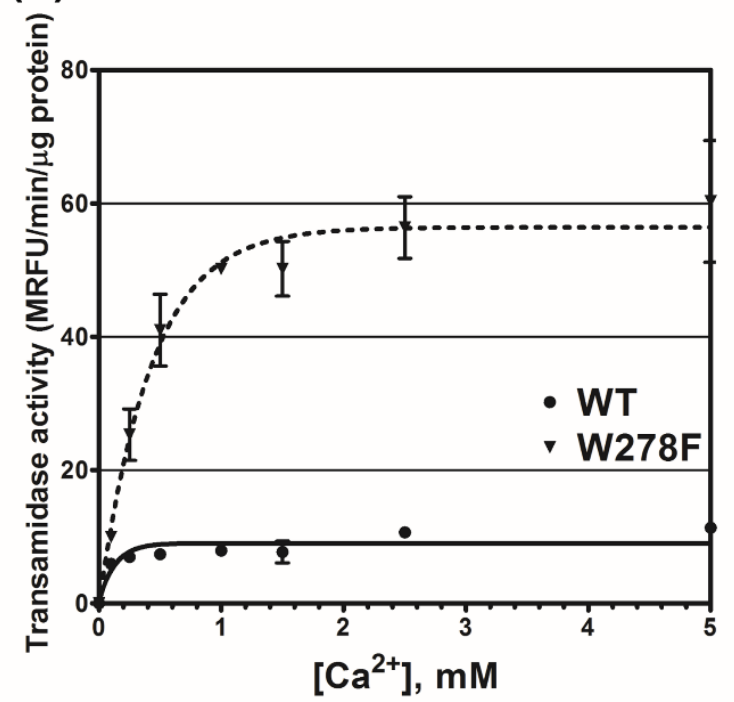

Fig. S1 $\mathrm{Ca}^{2+}$-dependence of isopeptidase (a) and transamidase (b) activities of the TG2-I and TG2-T mutants, respectively, in comparison with WT TG2 using kinetic activity assays. $\mathrm{EC}_{50}$ values based on the dose-response curves: Isopeptidase activity: TG2 WT EC $\mathrm{E}_{50}=0.44$; TG2-I $\mathrm{EC}_{50}=1.04$; Transamidase activity: TG2 WT EC $50=0.1$; TG2-T $\mathrm{EC}_{50}=0.96$ ). Data are presented as means with $\pm \mathrm{SD}$ from two separate experiments done in triplicate. 
(a)

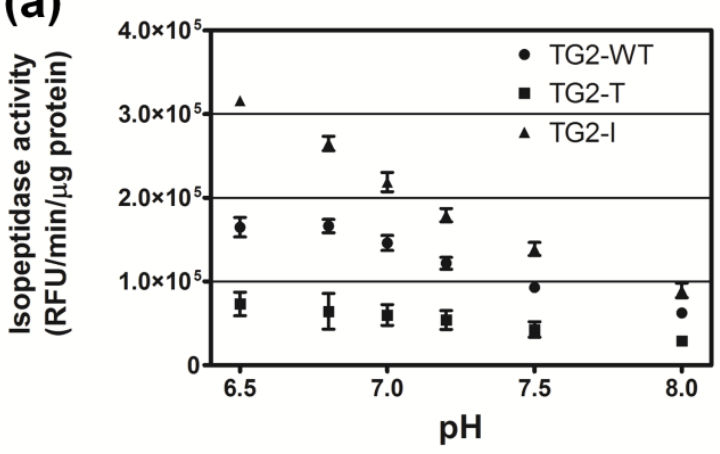

(b)

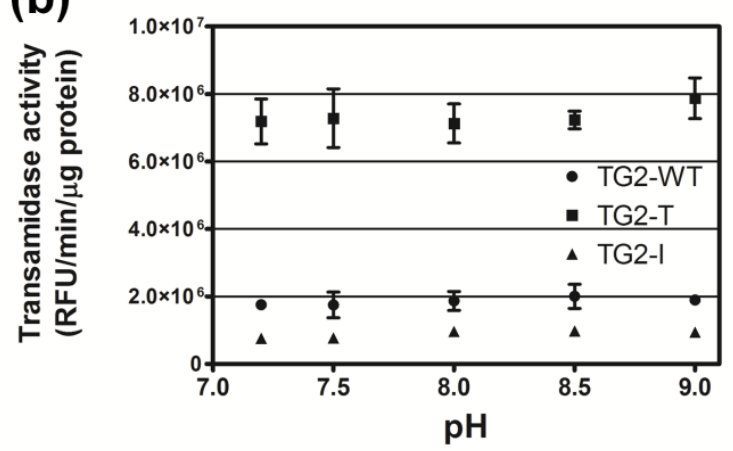

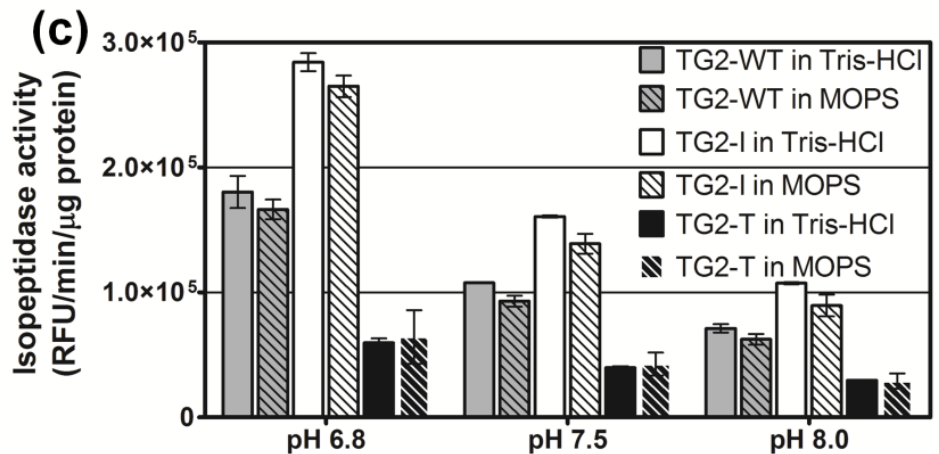

Fig. S2 Dependence of isopeptidase and transamidase reaction rate on different $\mathrm{pH}$. Kinetic MOPS buffer based isopeptidase (a) and Tris- $\mathrm{HCl}$ buffer based transamidase (b) assays were used to measure the effect of different $\mathrm{pH}$ values on isopeptidase and transamidase activities with addition of 10 or $0.83 \mu \mathrm{g}$ wild type or mutant TG2 enzymes, respectively. Comparison of isopeptidase activities using MOPS and Tris-HCl based buffers (c). Data are presented as means with $\pm \mathrm{SD}$ from two separate experiments done in duplicate. 
Mutation W332F influences the nucleotide binding without functional consequence

\begin{tabular}{|c|c|c|c|c|c|c|c|c|c|c|}
\hline \multirow[b]{2}{*}{$\begin{array}{c}\text { [Nucleotide] } \\
\mu \mathrm{M}\end{array}$} & \multicolumn{8}{|c|}{ Normalized isopeptidase activity (\%) } & \multicolumn{2}{|c|}{$\begin{array}{l}\text { Normalized } \\
\text { transamidase } \\
\text { activity }(\%)\end{array}$} \\
\hline & $\begin{array}{c}\text { TG2 } \\
\text { WT + } \\
\text { GTP } \gamma \mathrm{S} \\
+\mathbf{1} \mathbf{~ m M} \\
\mathrm{Ca}^{2+}\end{array}$ & $\begin{array}{c}\text { TG2 } \\
\text { WT + } \\
\text { GTP } \gamma \mathrm{S} \\
+10 \\
\mathrm{mM} \\
\mathrm{Ca}^{2+}\end{array}$ & $\begin{array}{c}\text { TG2-I+ } \\
\text { GTP } \gamma S \\
+1 \mathrm{mM} \\
\mathrm{Ca}^{2+}\end{array}$ & $\begin{array}{c}\text { TG2-I+ } \\
\text { GTP } \gamma \mathrm{S} \\
+10 \\
\mathrm{mM} \\
\mathrm{Ca}^{2+}\end{array}$ & $\begin{array}{c}\text { TG2 } \\
\text { WT + } \\
\text { GTP } \\
+1 \text { mM } \\
\mathrm{Ca}^{2+}\end{array}$ & $\begin{array}{c}\text { TG2 } \\
\mathrm{WT}+ \\
\mathrm{GTP}+ \\
10 \mathrm{mM} \\
\mathrm{Ca}^{2+}\end{array}$ & $\begin{array}{c}\text { TG2-I } \\
+ \text { GTP } \\
+1 \mathrm{mM} \\
\underset{\mathrm{Ca}^{2+}}{ }\end{array}$ & $\begin{array}{c}\text { TG2-I + } \\
\text { GTP } \\
+10 \mathrm{mM} \\
\mathrm{Ca}^{2+}\end{array}$ & $\begin{array}{c}\text { TG2 } \\
\text { WT + } \\
\text { GTP } \gamma \mathrm{S} \\
+1 \mathrm{mM} \\
\mathrm{Ca}^{2+}\end{array}$ & $\begin{array}{c}\text { TG2-T } \\
+ \\
\text { GTP } \gamma \mathrm{S} \\
+1 \mathrm{mM} \\
\mathrm{Ca}^{2+}\end{array}$ \\
\hline $\mathbf{0}$ & $\begin{array}{c}100.0 \pm \\
2.4\end{array}$ & $\begin{array}{c}100.0 \pm \\
1.3\end{array}$ & $\begin{array}{c}100.0 \pm \\
17.3\end{array}$ & $\begin{array}{c}100.0 \pm \\
14.7\end{array}$ & $\begin{array}{c}100.0 \pm \\
1.2\end{array}$ & $\begin{array}{c}100.0 \pm \\
9.9\end{array}$ & $\begin{array}{c}100.0 \pm \\
1.0\end{array}$ & $\begin{array}{c}100.0 \pm \\
6.2\end{array}$ & $\begin{array}{c}100.0 \pm \\
8.8\end{array}$ & $\begin{array}{c}100.0 \pm 3 \\
.4\end{array}$ \\
\hline 2 & $\begin{array}{l}7.8 \pm \\
0.6\end{array}$ & $\begin{array}{l}98.5 \pm \\
2.8\end{array}$ & $\begin{array}{c}26.9 \pm \\
6.1\end{array}$ & $\begin{array}{c}112.0 \pm \\
3.2\end{array}$ & $\begin{array}{c}16.2 \pm \\
0.6\end{array}$ & N/D & $\begin{array}{c}48.4 \pm \\
4.7\end{array}$ & N/D & $\begin{array}{c}87.8 \pm \\
7.1\end{array}$ & $\begin{array}{c}31.1 \pm 4 . \\
1\end{array}$ \\
\hline 5 & $\begin{array}{c}4.1 \pm \\
0.5\end{array}$ & $\begin{array}{l}99.5 \pm \\
3.3\end{array}$ & $\begin{array}{c}17.7 \pm \\
3.1\end{array}$ & $\begin{array}{c}111.4 \pm \\
3.7\end{array}$ & $\begin{array}{c}6.5 \pm \\
0.2\end{array}$ & N/D & $\begin{array}{c}29.8 \pm \\
1.1\end{array}$ & N/D & $\begin{array}{c}93.6 \pm \\
8.3\end{array}$ & $\begin{array}{c}19.1 \pm 5 . \\
5\end{array}$ \\
\hline 20 & $\begin{array}{c}2.2 \pm \\
0.3\end{array}$ & $\begin{array}{c}60.0 \pm \\
6.7\end{array}$ & $\begin{array}{c}10.8 \pm \\
1.1\end{array}$ & $\begin{array}{c}62.6 \pm \\
7.4\end{array}$ & $\begin{array}{c}2.9 \pm \\
0.6\end{array}$ & $\begin{array}{c}89.1 \pm \\
1.9\end{array}$ & $\begin{array}{c}16.2 \pm \\
0.4\end{array}$ & $\begin{array}{c}111.8 \pm \\
4.9\end{array}$ & $\begin{array}{c}69.4 \pm \\
30.6\end{array}$ & $4.7 \pm 0.6$ \\
\hline 100 & $\begin{array}{c}1.9 \pm \\
0.6 \\
\end{array}$ & $\begin{array}{c}22.4 \pm \\
3.0 \\
\end{array}$ & $\begin{array}{c}9.6 \pm \\
2.0 \\
\end{array}$ & $\begin{array}{c}28.3 \pm \\
2.3 \\
\end{array}$ & $\begin{array}{c}1.7 \pm \\
0.4 \\
\end{array}$ & $\begin{array}{c}43.6 \pm \\
1.9 \\
\end{array}$ & $\begin{array}{c}9.1 \pm \\
0.1 \\
\end{array}$ & $\begin{array}{c}60.3 \pm \\
0.9 \\
\end{array}$ & $\begin{array}{c}40.8 \pm \\
2.9 \\
\end{array}$ & $0.6 \pm 1.3$ \\
\hline $\begin{array}{c}\text { Approximate } \\
\text { IC50 values } \\
(\mu \mathrm{M}) \\
\end{array}$ & 0.47 & 20.6 & 0.8 & 20.1 & 0.7 & N/D & 1.7 & N/D & 22.6 & 0.9 \\
\hline
\end{tabular}

Table S1 Functional effect of nucleotides on isopeptidase and transamidase activities of mutant and WT TG2 enzymes. Table shows the dose responses for GTP $\gamma \mathrm{S}$ or GTP normalized to percent of activity in the absence of nucleotide. Different concentrations of the nucleotides were used in the presence of 1 or $10 \mathrm{mM} \mathrm{CaCl}_{2}$. Isopeptidase or kinetic transamidase assays contained 10 or $0.83 \mu \mathrm{g}$ of protein, respectively. Data are presented as means with \pm SD from two separate experiments done in triplicate. The data analysis was done by GraphPad Prism 5. 
(a)

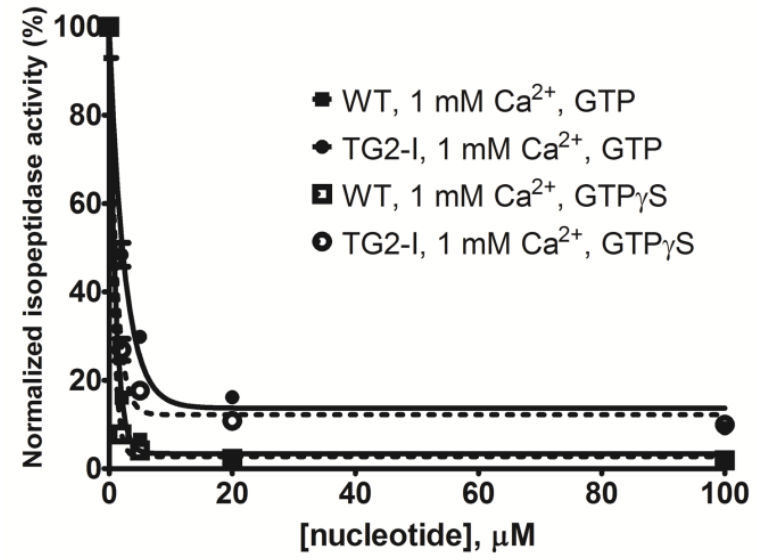

(b)

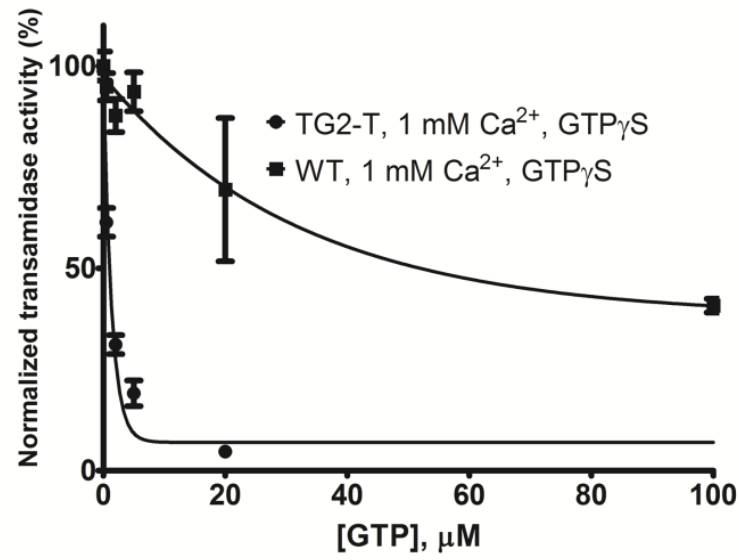

Fig. S3 Graphical comparison of the inhibitory effect of nucleotides on activities of mutant and WT TG2. The data are listed in the Table S1. (a) Dose response for GTP and GTP $\gamma$ S normalized to percent of isopeptidase activity in the absence of nucleotides. Different concentrations of GTP or GTP $\gamma \mathrm{S}$ were used in the presence of 1 $\mathrm{mM} \mathrm{CaCl} 2$ and $10 \mu \mathrm{g}$ of protein. (b) Dose response for GTP $\gamma \mathrm{S}$ normalized to percent of kinetic transamidase activity in the absence of nucleotide. Different concentration of GTP $\gamma \mathrm{S}$ was used in the presence of $1 \mathrm{mM} \mathrm{CaCl}_{2}$ and $0.5 \mu \mathrm{g}$ of enzymes. 